J Arid Land (2014) 6(1): 44-58

doi: $10.1007 / \mathrm{s} 40333-013-0176-9$

jal.xjegi.com; www.springer.com/40333

\title{
Soil salt leaching under different irrigation regimes: HYDRUS-1D modelling and analysis
}

\author{
WenZhi ZENG, Chi XU, JingWei WU*, JieSheng HUANG \\ State Key Laboratory of Water Resources and Hydropower Engineering Science, Wuhan University, Wuhan 430072, China
}

\begin{abstract}
Field irrigation experiments were conducted in the Hetao Irrigation District of Inner Mongolia, China, to study the effects of irrigation regimes on salt leaching in the soil profile. The data were used to calibrate and validate the HYDRUS-1D model. The results demonstrated that the model can accurately simulate the water and salt dynamics in the soil profile. The HYDRUS-1D model was then used to simulate 15 distinct irrigation scenarios. The results of the simulation indicated that irrigation amount did not have a significant effect on soil water storage but that increases in irrigation amount could accelerate salt leaching. However, when the irrigation amount was larger than $20 \mathrm{~cm}$, the acceleration was not obvious. Compared with irrigating only once, intermittent irrigation had a better effect on increasing soil water storage and salt leaching, but excessive irrigation times and intervals did not improve salt leaching. In addition, we found that the irrigation regime of $20 \mathrm{~cm}$, irrigated twice at 1-d intervals, might significantly increase salt leaching in the plough layer and decrease the risks of deep seepage and groundwater contamination.
\end{abstract}

Keywords: numerical simulation; optimal irrigation regime; secondary salinization; water and salt dynamics

Citation: WenZhi ZENG, Chi XU, JingWei WU, JieSheng HUANG. 2014. Soil salt leaching under different irrigation regimes: HYDRUS-1D modelling and analysis. Journal of Arid Land, 6(1): 44-58. doi: 10.1007/s40333-013-0176-9

Irrigation has significantly contributed to increased crop production worldwide. Unfortunately, irrigation has also led to secondary salinization of agricultural lands and has caused the destruction of these lands in many regions because of the use of brackish water or inappropriate irrigation regimes (Van Schilfgaarde, 1994). Researchers have shown that approximately $2 \times 10^{7}-3 \times 10^{7} \mathrm{hm}^{2}$ of irrigated land have been seriously damaged and degraded by secondary salinization and that approximately $1.5 \%$ of the land is estimated to be permanently lost from production. China has a large area of salt-affected soil. It is the second largest country, following India, which is affected by irrigation-induced soil salinization (Sankaran et al., 2012). Statistical data indicated that along Northern China there distributed approximately $7.6 \times 10^{6} \mathrm{hm}^{2}$ of salinized land that would otherwise be available for cultivation. The Hetao Irrigation District, located in
Northern China, is the largest irrigation district in China. For land with serious soil salinization problems, a flood-irrigation system has been in development since the 1980s to reduce the salinity levels in the root zone and increase the water availability for the following spring crops (Meng and Yang, 2002). However, this irrigation system may cause water waste and secondary salinization of the soil; furthermore, it may also increase the risk of groundwater contamination because a large amount of nitrogen and salt could leach deep into the soil with the irrigation water.

Despite its negative impacts, irrigation is important for sustaining and increasing agricultural production. In 2002, the FAO (Food and Agriculture Organization) noted that while roughly $17 \%$ of the world's agricultural land is irrigated, this $17 \%$ yields roughly $40 \%$ of the total global food harvest. Furthermore, per capita arable land has decreased by $26.3 \%$ (from $0.38 \mathrm{hm}^{2}$ to

*Corresponding author: JingWei WU (E-mail: wujingweiwhu@gmail.com) Received 2013-01-08; revised 2013-02-27; accepted 2013-04-18

(C) Xinjiang Institute of Ecology and Geography, Chinese Academy of Sciences, Science Press and Springer-Verlag Berlin Heidelberg 2013 
$0.28 \mathrm{hm}^{2}$ ) in almost 30 years, and some analysts predict a further decrease to $0.15 \mathrm{hm}^{2}$ by 2050 (Ghassemi et al., 1995). Therefore, the only way to increase production is by improving irrigation regimes and increasing irrigation efficiency.

Different irrigation regimes have different salt leaching effects. Irrigation frequency (intervals and times) also has a significant effect on salt leaching (Nachabe et al., 1999). Moreover, intermittent highfrequency irrigation with less water has become a common practice since the development and spread of water-saving irrigation technologies. Meanwhile, computer models have become increasingly important tools for analysing irrigation, soil salinization, and crop production problems (Skaggs et al., 2006; Ramos et al., 2011; Tafteh and Sepaskhah, 2012). HYDRUS-1D was developed by the USDA Salinity Laboratory and has been used to study the leaching of accumulated salt and nitrogen in the soil profile under heavy rainfall and high rates of irrigation during the growing season. In flood irrigation, water infiltrates the surface soil layer both horizontally and vertically, causing the salt movement to be two-dimensional as well. However, investigators who compared two-dimensional simulation models (HYDRUS-2D) with HYDRUS-1D found that HYDRUS-1D produced an accurate simulation of water and salt movement during flood irrigation and precipitation. Furthermore, HYDRUS-1D is simpler and easier to use than its 2D counterpart, which has not generated very accurate findings (Crevoisier et al., 2008; Ahmadi et al., 2010).

The first objective of this study was to evaluate HYDRUS-1D modelling as a simulation of water and salt movement during flood irrigation using observational data from field experiments. The second objective was to use HYDRUS-1D to find an optimal irrigation regime for the Hetao Irrigation District by analysing water and salt movements in different irrigation regimes.

\section{Materials and methods}

\subsection{Study area}

The Hetao Irrigation District $\left(40^{\circ} 19^{\prime}-41^{\circ} 18^{\prime} \mathrm{N}\right.$, $106^{\circ} 20^{\prime}-109^{\circ} 19^{\prime} \mathrm{E}$ ), which is situated in the arid west- ern areas of Inner Mongolia autonomous region, is one of the three largest irrigation districts in China. The average annual precipitation is $139-222 \mathrm{~mm}$, approximately $60 \%$ of which falls in July and August. The annual potential evaporation is approximately 2,200-2,400 $\mathrm{mm}$. Strong evaporation makes the groundwater and soil water constantly migrate upward; eventually resulting in salt accumulation in the soil surface after the soil water evaporates. As a result, the Hetao Irrigation District has struggled with soil salinization issues for several years. Researchers have shown that approximately half of the irrigated cropland in the district is saline-alkali soil. From 1987 to 1997, the average annual salt accumulation was estimated to be $3,000 \mathrm{~kg} / \mathrm{hm}^{2}$ (Feng et al., 2003).

Field experiments were conducted at the Yichang experimental station in the Hetao Irrigation District. Specifically, we set 36 simple lysimeters containing undisturbed soil and an observation well in $300 \mathrm{~m}^{2}$ of barren land. The cross section of each lysimeter was $1.8 \mathrm{~m} \times 1.8 \mathrm{~m}$, and they were wrapped with impermeable plastic $(0-1.5 \mathrm{~m}$ below the soil surface) to prevent leakage (Fig. 1).



Fig. 1 Schematic of a simple lysimeter

In Hetao, irrigation peaks during growth periods and the fall irrigation. During crop growth periods, irrigation is used to meet the water demands of the crops; the irrigation amounts vary depending on the plant structure. The fall irrigation is the period to focus on salt leaching because the annual peak of irrigation amount occurs at this time (approximately Sep- 
tember to October annually), and salt accumulation and leaching in the soil profile are also very frequent during this period.

\subsection{Experiment design}

To reduce salinity levels in the soil and increase the water availability for the following spring crops, we irrigated 36 simple lysimeters on 26 October 2012. Before irrigation (24 October 2012), we took soil samples from the 36 lysimeters to determine the water and salt contents at depths of $0-5,5-10,10-20,20-40$, $40-60,60-80$, and $80-100 \mathrm{~cm}$ of each soil profile. For the sampling analysis, we chose 4 lysimeters that had similar initial soil water and salt profiles at a depth of $0-100 \mathrm{~cm}$ to study the effects of different irrigation regimes on soil salt leaching. Specifically, we lettered these 4 lysimeters by A, B, C, and D, respectively, and the physical properties of their soil profiles are shown in Table 1. The irrigation water came from a well. It had a salinity of $0.2 \mathrm{~g} / \mathrm{L}$, which is equal to $3.4 \mathrm{mmol} / \mathrm{L}$ of dissolved $\mathrm{NaCl}$. The ion composition of irrigation water is shown in Table 2. The irrigation amount of lysimeters A and B was $0.648 \mathrm{~m}^{3}$, while the value of lysimeters $C$ and $D$ was $0.972 \mathrm{~m}^{3}$. The irrigation water was only used once. We took soil samples for water and salt content measurements $10 \mathrm{~d}$ after irrigation. The sampling depth remained the same.

\subsection{Soil analysis}

The soil water content was evaluated using conventional oven drying. The electrical conductivity (EC) of the soil was determined with an EC analyser (DDSJ-318, LeiCi, Shanghai, China) in an extract (1:5) after shaking for 3 mins. The total dissolved salt content (\%) of the soil was estimated using a linear regression equation (Eq. 1) relating the total salinity and the measured EC values of the calibration results from the Yichang experimental station.

$$
\text { Total salt content }=0.41 \times E C_{1: 5} \text {. }
$$

To simplify the simulation process, we assumed that the measured soil salt content was the $\mathrm{NaCl}$ content using Eq. 2.

$$
\text { Total salt content }=\frac{0.41 \times E C_{1: 5} \times m_{\mathrm{dry} \text { soil }}}{58.5} \times 1000 \text {. }
$$

We can calculate the total soil water and salt storage of the lysimeters at any specified time using Eq. 3 and Eq. 4:

$$
\begin{gathered}
W_{i}=\sum_{j=0}^{n} \theta\left(j, t_{i}\right) \Delta Z_{j}, \\
m_{i}=\sum_{j=0}^{n}\left[\theta\left(j, t_{i}\right) c\left(j, t_{i}\right) \Delta Z_{j}\right] .
\end{gathered}
$$

Where, $W_{i}$ is the total soil water storage of the lysimeters at time $t_{i}(\mathrm{~cm}) ; \Delta Z$ is the thickness of the soil layer $(\mathrm{cm}) ; n$ is the total number of soil layers; and $\theta\left(j, t_{i}\right)$ is the soil volumetric moisture content of layer $j$ at time $t_{i}\left(\mathrm{~cm}^{3} / \mathrm{cm}^{3}\right) ; m_{i}$ is the total soil water storage of the lysimeters at time $t_{i}(\mathrm{~cm})$, and $\mathrm{c}\left(j, t_{i}\right)$ is the soil salt concentration of layer $j$ at $t_{i}\left(\mathrm{~cm}^{3} / \mathrm{cm}^{3}\right)$.

\subsection{HYDRUS-1D model}

\subsubsection{Water movement}

We observed much larger macropores in the lysimeters after irrigation. To explain the significant effect of preferential flow on these lysimeters, we selected a

\begin{tabular}{|c|c|c|c|c|c|c|c|c|}
\hline Total dissolved solid & $\mathrm{CO}_{3}^{2-}$ & $\mathrm{HCO}_{3}^{-}$ & $\mathrm{Cl}^{-}$ & $\begin{array}{c}\mathrm{SO}_{4}{ }^{2-} \\
(\mathrm{mg} / \mathrm{L})\end{array}$ & $\mathrm{Ca}^{2+}$ & $\mathrm{Mg}^{2+}$ & $\mathrm{Na}^{+}$ & $\mathrm{K}^{+}$ \\
\hline 200 & 0 & 44.97 & 60.67 & 22.50 & 0.60 & 0.83 & 57.13 & 13.29 \\
\hline
\end{tabular}

Table 1 Physical properties of the soil profile at the Yonglian experimental site

\begin{tabular}{ccccccc}
\hline Soil layer $(\mathrm{cm})$ & Bulk density $\left(\mathrm{g} / \mathrm{cm}^{3}\right)$ & \multicolumn{3}{c}{ Particle fraction $(\%)$} & \multirow{2}{*}{ Texture $($ USDA) } & Organic matter $(\mathrm{g} / \mathrm{kg})$ \\
\cline { 3 - 5 } & & Clay & Silt & Sand & & Loamy sand \\
$0-30$ & 1.35 & 6.61 & 20.13 & 73.26 & 5.51 \\
$30-50$ & 1.44 & 5.25 & 12.45 & 82.30 & Loamy sand \\
$50-100$ & 1.51 & 15.18 & 47.69 & 37.13 & Loam \\
\hline
\end{tabular}

Table 2 Ion composition of irrigation water

Note: $\mathrm{CO}_{3}{ }^{2-}$ and $\mathrm{HCO}_{3}{ }^{-}$were measured by titration with double indicators (Yu et al., 2010). Other ions were measured by ion chromatograph (CIC-200, Shenghan, Qingdao, China) 
dual-porosity flow model for HYDRUS-1D. The dual-porosity water flow model is based on a combination of the Richards equation, to describe water flow in the macropores (mobile water region), and a mass balance equation, to describe moisture dynamics in the matrix (immobile water region) (Simunek et al., 2003). The formulation used is as follows:

$$
\begin{gathered}
\frac{\partial \theta_{m}}{\partial t}=\frac{\partial}{\partial z}\left[K(h)\left(\frac{\partial h}{\partial z}+1\right)\right]-\Gamma_{w}, \\
\frac{\partial \theta_{i m}}{\partial t}=\Gamma_{w} .
\end{gathered}
$$

Here, the subscripts $m$ and $i m$ refer to the mobile and immobile water regions, respectively; $\theta=\theta_{m}+\theta_{\text {im }}$ is the volumetric moisture content $\left(\mathrm{cm}^{3} / \mathrm{cm}^{3}\right)$, and $\Gamma_{w}$ is the transfer rate for water change between the macropores and the matrix (/d). We assumed this exchange rate in the dual-porosity flow model based on the mass transfer driven by the fact that the difference in the soil water pressure head is proportional to the difference in the pressure heads between the two pore regions (Gerke et al., 1993):

$$
\Gamma_{w}=w\left(h_{m}-h_{i m}\right) .
$$

Here, $w$ is a first-order mass transfer coefficient (/(cm.d)).

\subsubsection{Solute transport}

We used a two-region mobile-immobile model (MIM) to simulate solute transport. The MIM assumes that solute transport is limited to the mobile water region and that water in the immobile water region is stagnant, with a first-order diffusive exchange process between the two regions. Because we did not consider salt sorption and neglected the soil-salt reaction, the following simplified MIM was used in this study to simulate salt transport (Neumann et al., 2011; Tafteh and Sepaskhah, 2012).

$$
\begin{gathered}
\frac{\partial \theta_{m} C_{m}}{\partial t}=\frac{\partial}{\partial z}\left(\theta_{m} D_{m} \frac{\partial C_{m}}{\partial z}\right)-\frac{\partial q C_{m}}{\partial z}-\Gamma, \\
\theta_{i m} \frac{\partial C_{i m}}{\partial t}=\Gamma .
\end{gathered}
$$

Here, $C$ is the concentration in the liquid phase $\left(\mathrm{mmol} / \mathrm{cm}^{3}\right), \quad D$ is the dispersion coefficient $\left(\mathrm{cm}^{2} / \mathrm{d}\right)$, and $\Gamma$ is the term for mass transfer between the two regions $\left(\mathrm{mmol} /\left(\mathrm{cm}^{3} \cdot \mathrm{d}\right)\right)$.

\subsubsection{Evaluation of model performance}

The model was evaluated using two methods: graphical and statistical. In the graphical approach, volumetric moisture and soil salinity were measured, simulated, and plotted as a function of soil depth. Two statistical procedures were used to assess the level of agreement between the predicted and observed data:

(i) Root mean square error (RMSE):

$$
R M S E=\sqrt{\sum_{i=1}^{n} \frac{\left(P_{i}-O_{i}\right)^{2}}{n}}
$$

(ii) Nash-Sutcliffe modelling efficiency (NSE) (Nash and Sutcliffe, 1970):

$$
N S E=1-\frac{\sum_{i=1}^{n}\left(O_{i}-P_{i}\right)^{2}}{\sum_{i=1}^{n}\left(O_{i}-O\right)^{2}} .
$$

Here, $P_{i}$ is the predicted value corresponding to the observed value $O_{i}$, and $n$ is the number of data pairs. $O$ is the observed mean.

The closer the RMSE is to 0 , the more accurate the model is. NSE can range from $-\infty-1$. An efficiency of 1 corresponds to a perfect match between the modelled values and the observed data. NSE $=0$ indicates that the model predictions are as accurate as the mean of the observed data, whereas an NSE of less than zero occurs when the observed mean is a better predictor than the model. Generally, the closer the NSE is to 1 , the more accurate the model is.

\subsubsection{Calibration and validation}

Because pressure heads were needed for both regions, we divided the studied soil layer $(0-100 \mathrm{~cm})$ into two parts to calibrate and validate the parameters $(0-50 \mathrm{~cm}$, $50-100 \mathrm{~cm})$. Therefore, the soil hydraulic properties are described by six parameters for macropores $\left(\theta_{r}, \theta_{s}\right.$, $\left.\alpha, n, K_{s}, l\right)$, four parameters for the matrix $\left(\theta_{r-i m}, \theta_{s-i m}\right.$, $\left.\alpha_{i m}, n_{i m}\right)$, and one parameter ( $\left.w\right)$ for mass transfer between the two zones (Simunek et al., 2003). To reduce the number of parameters to optimise, we assumed that there was no residual water in the matrix $\left(\theta_{r-i m}=0\right)$, which we determined from the soil texture and bulk density (Schaap et al., 2001). Inverse modelling was used to determine the shape parameters $\left(\alpha, \alpha_{i m}, n, n_{i m}\right)$. The saturated hydraulic conductivity $\left(K_{s}\right)$ was determined using soil sampling analyses of lysimeter A and 
lysimeter B $10 \mathrm{~d}$ after irrigation. The input values are shown in Table 3.

The upper conditions of the soil profile correspond to atmospheric BC (Boundary Condition), with a surface layer at which rainfall and evaporation have been measured by an automatic weather station (SY.51-YYZ, ZhuoChuan Company, China). Because the groundwater depth was approximately $240 \mathrm{~cm}$ and we only focused on the $0-100 \mathrm{~cm}$ soil profile, the lower boundary condition was free drainage. For sol- ute transport, the upper and lower boundary conditions were concentration flux $\mathrm{BC}$ and zero concentration gradient.

We validated the model according to the soil sampling analyses of lysimeter C and lysimeter D $10 \mathrm{~d}$ after irrigation.

Figures 2, 3 and Table 4 provide the calibration and validation results of the HYDRUS-1D model. We found that the predicted values fit well with the measured values with respect to water and salt movement

Table 3 Input values of the hydrodynamic parameters

\begin{tabular}{|c|c|c|c|c|c|c|c|c|c|}
\hline $\begin{array}{l}\text { Depth } \\
\text { (cm) }\end{array}$ & $\begin{array}{c}\theta_{r} \\
\left(\mathrm{~cm}^{3} / \mathrm{cm}^{3}\right)\end{array}$ & $\begin{array}{c}\theta_{s} \\
\left(\mathrm{~cm}^{3} / \mathrm{cm}^{3}\right)\end{array}$ & $\begin{array}{c}\alpha \\
(/ \mathrm{cm})\end{array}$ & $\begin{array}{l}n \\
-\end{array}$ & $\begin{array}{c}K_{s} \\
(\mathrm{~cm} / \mathrm{d})\end{array}$ & $\begin{array}{c}\theta_{s-i m} \\
\left(\mathrm{~cm}^{3} / \mathrm{cm}^{3}\right)\end{array}$ & $\begin{array}{c}\alpha_{i m} \\
(/ \mathrm{cm})\end{array}$ & $\begin{array}{l}n_{i m} \\
-\end{array}$ & $\begin{array}{c}w \\
(/(\mathrm{cm} \cdot \mathrm{d}))\end{array}$ \\
\hline $0-50$ & 0.054 & 0.43 & 0.013 & 1.909 & 8.97 & 0.008 & 1.007 & 1.402 & 0.001 \\
\hline $50-100$ & 0.085 & 0.48 & 0.099 & 1.788 & 3.37 & 0.012 & 0.786 & 1.278 & 0.026 \\
\hline
\end{tabular}
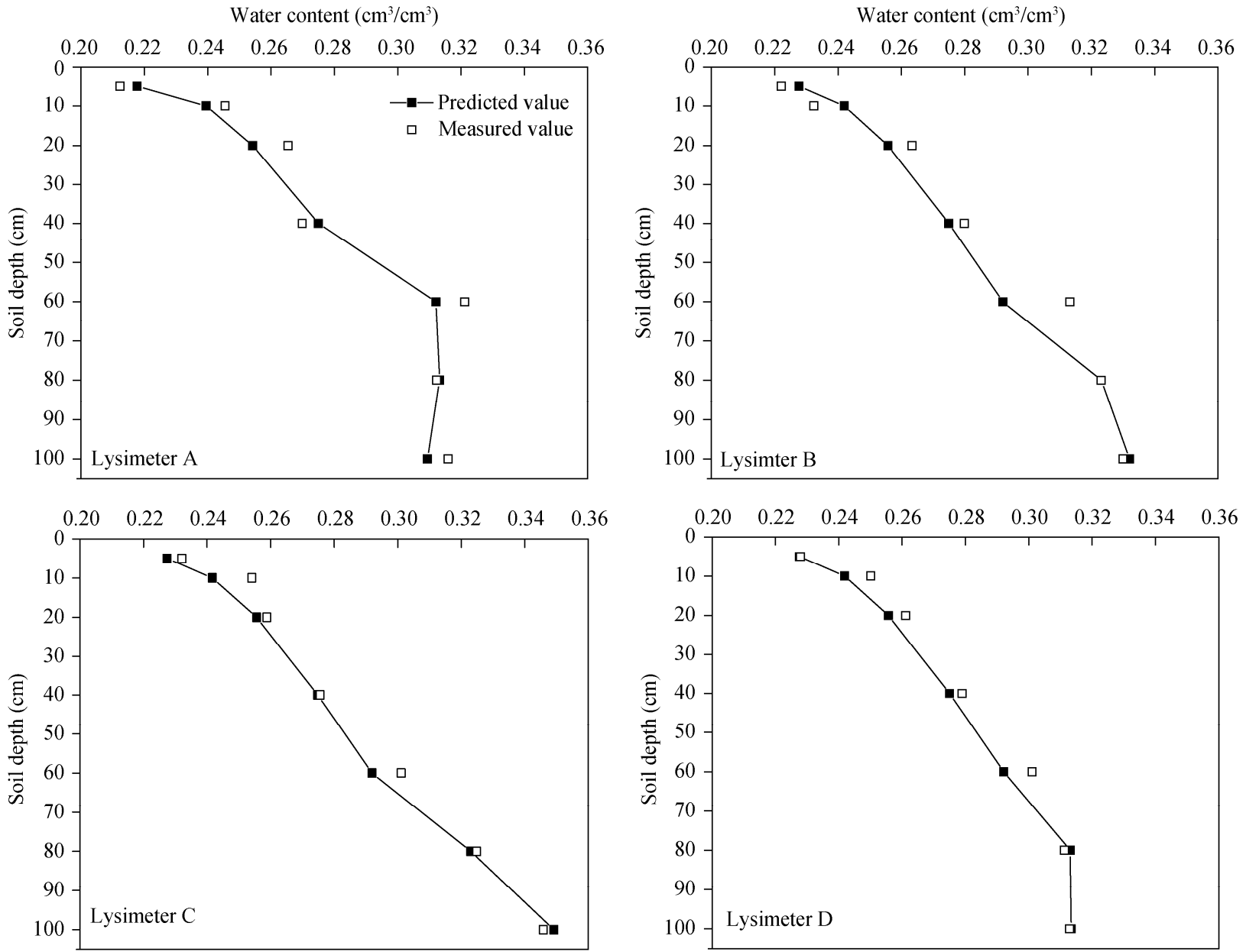

Fig. 2 Calibration and verification of soil water content (The average soil water contents of the depths 0-5, 5-10, 10-20, 20-40, 40-60, $60-80$, and $80-100 \mathrm{~cm}$ are presented as the values at $5,10,20,40,60,80$, and $100 \mathrm{~cm}$, respectively.) 

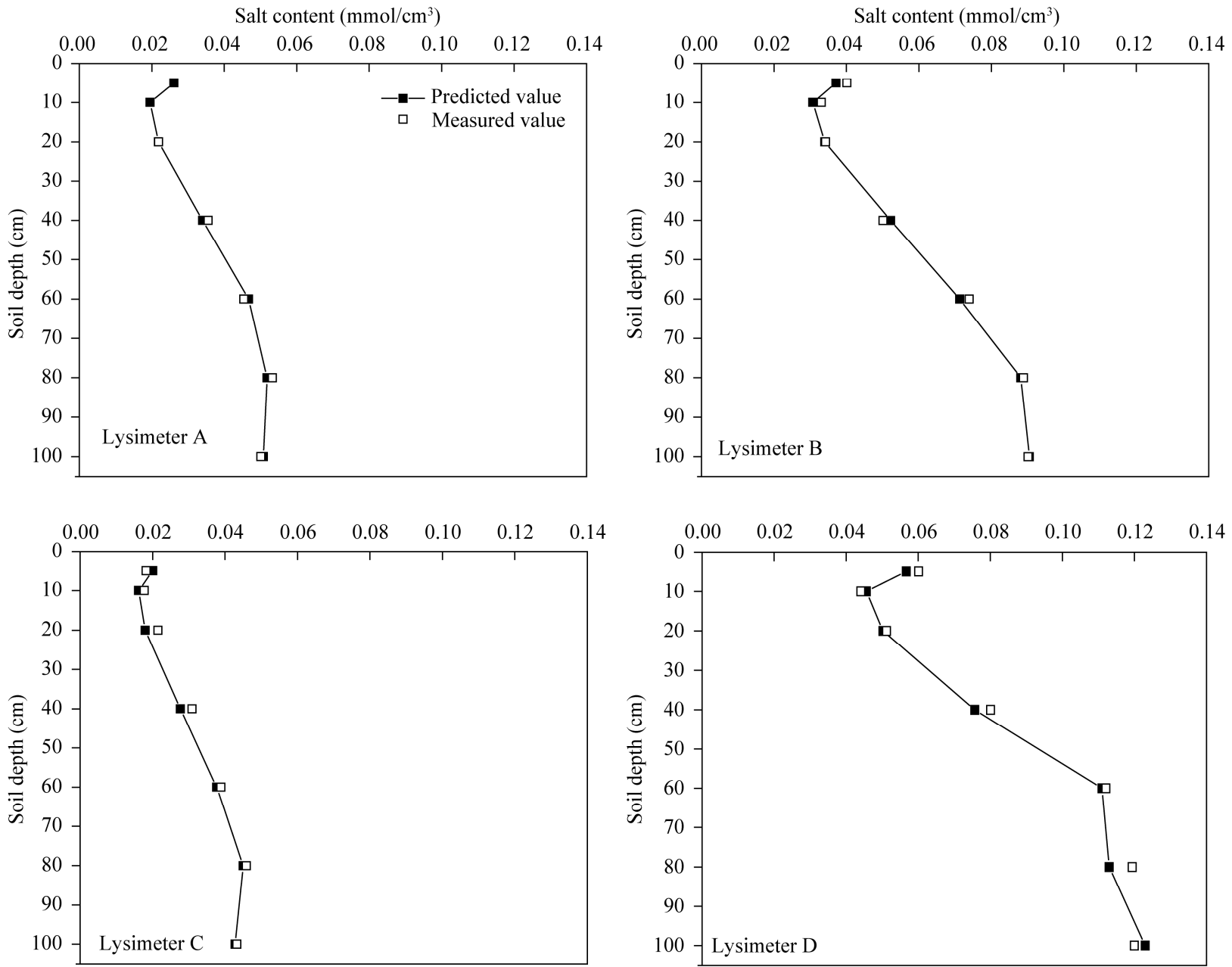

Fig. 3 Calibration and verification of soil salt contents (The average soil salt contents of the depths 0-5, 5-10, 10-20, 20-40, 40-60, $60-80$, and $80-100 \mathrm{~cm}$ are presented as the values at $5,10,20,40,60,80$, and $100 \mathrm{~cm}$, respectively.)

Table 4 Model performance statistics for predicted water content and salt content under different treatments for model calibration and validation

\begin{tabular}{lcccc}
\hline \multirow{2}{*}{ Treatment } & \multicolumn{2}{c}{ Water content $\left(\mathrm{cm}^{3} / \mathrm{cm}^{3}\right)$} & \multicolumn{2}{c}{ Salt content $\left(\mathrm{mmol} / \mathrm{cm}^{3}\right)$} \\
\cline { 2 - 5 } & RMSE & NSE & RMSE & NSE \\
\hline A0-40 cm & 0.0103 & 0.7942 & 0.0031 & 0.7361 \\
A40-100 cm & 0.0180 & 0.6563 & 0.0012 & 0.9989 \\
B0-40 cm & 0.0102 & 0.8500 & 0.0022 & 0.8934 \\
B40-100 cm & 0.0200 & 0.4865 & 0.0077 & 0.8871 \\
C0-40 cm & 0.0068 & 0.8063 & 0.0027 & 0.7477 \\
C40-100 cm & 0.0130 & 0.4973 & 0.0010 & 0.9002 \\
D0-40 cm & 0.0053 & 0.9180 & 0.0029 & 0.9531 \\
D40-100 cm & 0.0073 & 0.7843 & 0.0084 & 0.6989 \\
\hline
\end{tabular}

in the soil profile. The RMSE values of the water and salt contents at a depth of $0-100 \mathrm{~cm}$ of all 4 lysimeters were below 0.02 . The NSE values of the water and salt contents at a depth of $0-40 \mathrm{~cm}$ ranged from 0.73 to 0.96 . Although the $40-100 \mathrm{~cm}$ NSE values were less than 0.5 in some treatments, we can state that HYDRUS-1D showed relatively good agreement between the simulated results and the measured data.

\subsubsection{Simulation schemes}

Although the calibration and verification of model parameters were only according to irrigation amount in our study, a large number of HYDRUS-1D applications in different climates proved the good performance of HYDRUS-1D to simulate soil water and salt transport under different precipitation and evaporation conditions (Neumann et al., 2011; Tafteh and Sepaskhah, 2012; Dabach et al., 2013). Therefore, for better understanding the effect of different irrigation regimes (irrigating once and intermittent irrigation) on 
soil salt leaching, we chose irrigation amount, irrigation times and irrigation intervals as study factors and established three levels for each factor for the simulation (Table 5). The starting point for the modelling was the time of the initial irrigation, and the end point was $10 \mathrm{~d}$ after irrigation.

We used the average water and salt values from 36 lysimeters at a depth of $0-100 \mathrm{~cm}$ on 24 October as the initial soil profile (Table 6). We neglected precipitation during the time of the simulation and set the evaporation rate as $2 \mathrm{~mm} / \mathrm{d}$.

Table 5 Irrigation amount, times and interval of the modelling

\begin{tabular}{cccc}
\hline Treatment & $\begin{array}{c}\text { Irrigation } \\
\text { amount } \\
(\mathrm{cm})\end{array}$ & $\begin{array}{c}\text { Irrigation } \\
\text { times }\end{array}$ & $\begin{array}{c}\text { Irrigation } \\
\text { interval } \\
(\text { day })\end{array}$ \\
\hline 1 & 10 & 1 & 0 \\
2 & 20 & 1 & 0 \\
3 & 30 & 1 & 0 \\
4 & 10 & 2 & 1 \\
5 & 10 & 2 & 2 \\
6 & 10 & 3 & 1 \\
7 & 10 & 3 & 2 \\
8 & 20 & 2 & 1 \\
9 & 20 & 2 & 2 \\
10 & 20 & 3 & 1 \\
11 & 20 & 3 & 2 \\
12 & 30 & 2 & 1 \\
13 & 30 & 2 & 2 \\
14 & 30 & 3 & 1 \\
15 & 30 & 3 & 2 \\
\hline
\end{tabular}

Table 6 Initial water and salt contents of the soil profile used for modelling

\begin{tabular}{ccc}
\hline $\begin{array}{c}\text { Depth } \\
(\mathrm{cm})\end{array}$ & $\begin{array}{c}\text { Water content } \\
\left(\mathrm{cm}^{3} / \mathrm{cm}^{3}\right)\end{array}$ & $\begin{array}{c}\text { Salt content } \\
\left(\mathrm{mmol} / \mathrm{cm}^{3}\right)\end{array}$ \\
\hline $0-5$ & 0.347 & 0.22 \\
$5-10$ & 0.324 & 0.19 \\
$10-20$ & 0.301 & 0.17 \\
$20-40$ & 0.350 & 0.13 \\
$40-60$ & 0.397 & 0.07 \\
$60-80$ & 0.396 & 0.10 \\
$80-100$ & 0.376 & 0.14 \\
\hline
\end{tabular}

\section{Results and discussion}

\subsection{The effects of different irrigation amounts}

The effects of different irrigation amounts on soil wa- ter storage are illustrated in Fig. 4. This figure shows that the irrigation amount initially increased and then decreased gradually over time. This trend can be explained by the influence of infiltration and evaporation. In this simulation, however, different irrigation amounts did not have a significant influence on soil water storage after irrigating once (Figs. $4 a-c)$. This result is because the soil in the research area is loamy sand, which has a high hydraulic conductivity. Moreover, the long-time interval $(1 \mathrm{~d})$ used in the simulation caused the simulation result to be insensitive to the irrigation. However, with intermittent infiltration (Figs. $4 \mathrm{~d}-\mathrm{i}$ ), as the irrigation amount increased from 10 to $20 \mathrm{~cm}$, the soil water storage increased greatly. For instance, the soil horizons of $0-20,0-40$, and 0-100 $\mathrm{cm}$ corresponded to the largest increases: $4.88 \%, 5.91 \%$, and $9.69 \%$, respectively. When the irrigation amount increased from 20 to $30 \mathrm{~cm}$, soil water storage did not increase significantly. Therefore, we conclude that excessive irrigation is of little significance to increasing the soil water storage. Comparing Figs. 4d-i with Figs. $4 \mathrm{a}-\mathrm{c}$, we can see that soil water storage has two peaks and that the decrease in soil water storage over $0-4 \mathrm{~d}$ is less with intermittent irrigation than when irrigation is performed once. This result demonstrates that, to a certain extent, intermittent irrigation contributes to maintaining the humidity in the soil.

Different irrigation amounts had a variety of influences on soil salt storage, as Fig. 5 exhibits. The figure shows that regardless of whether irrigation occurred once or intermittently, soil salt storage at different depths decreased as the irrigation amount increased, which demonstrates the salt leaching effect of irrigation water on soil salt. When the irrigation amount increased from 10 to $20 \mathrm{~cm}$ after irrigating once, the salt storage in soil at $0-20,0-40$, and $0-100$ $\mathrm{cm}$ decreased by approximately $15.50 \%, 13.58 \%$, and $5.70 \%$, respectively (Figs. 5a-c). After intermittent irrigation, the decrease was greater: $15.50 \%, 13.58 \%$, and $5.70 \%$, respectively (Figs. $5 \mathrm{~d}-\mathrm{f}$ ). However, when the irrigation amount increased from 20 to $30 \mathrm{~cm}$, the decreases in the soil salt storage were different: $2.3 \%$, $1.9 \%, 0.75 \%$ for the former (Figs. $5 \mathrm{a}-\mathrm{c}$ ) and $22.23 \%$, $19.44 \%, 11.59 \%$ for the latter (Figs. 5a-c), respec- 

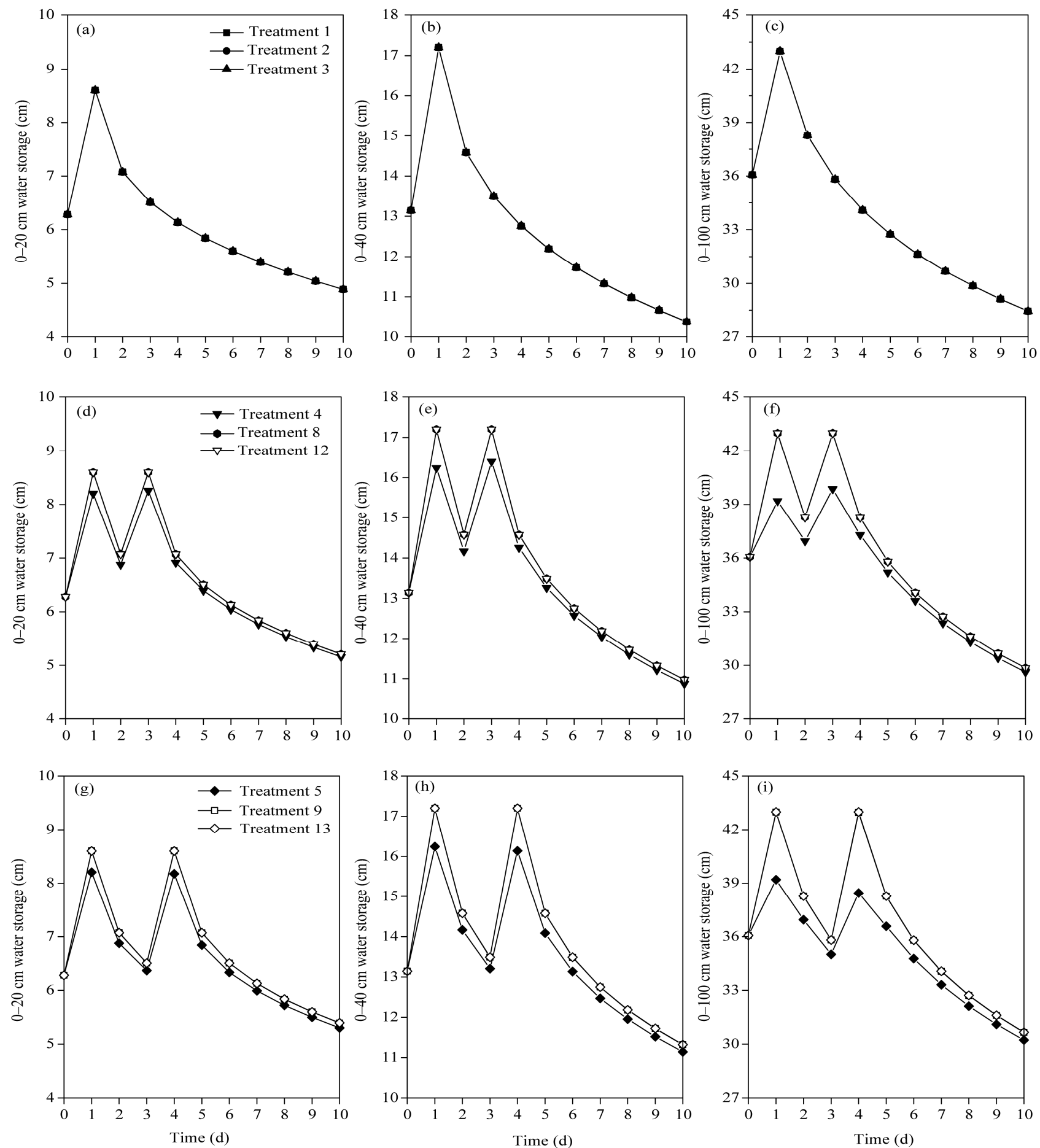

Fig. 4 Effect of irrigation amount on soil water storage

tively. This observation proved that the salt leaching effect of intermittent irrigation is superior to that of irrigating once under the same circumstances. Further, excessive irrigation did not promote the leaching effect.

\subsection{The effect of different frequencies of inter- mittent infiltration}

The relationship between soil water storage and time under different frequencies of intermittent infiltration 

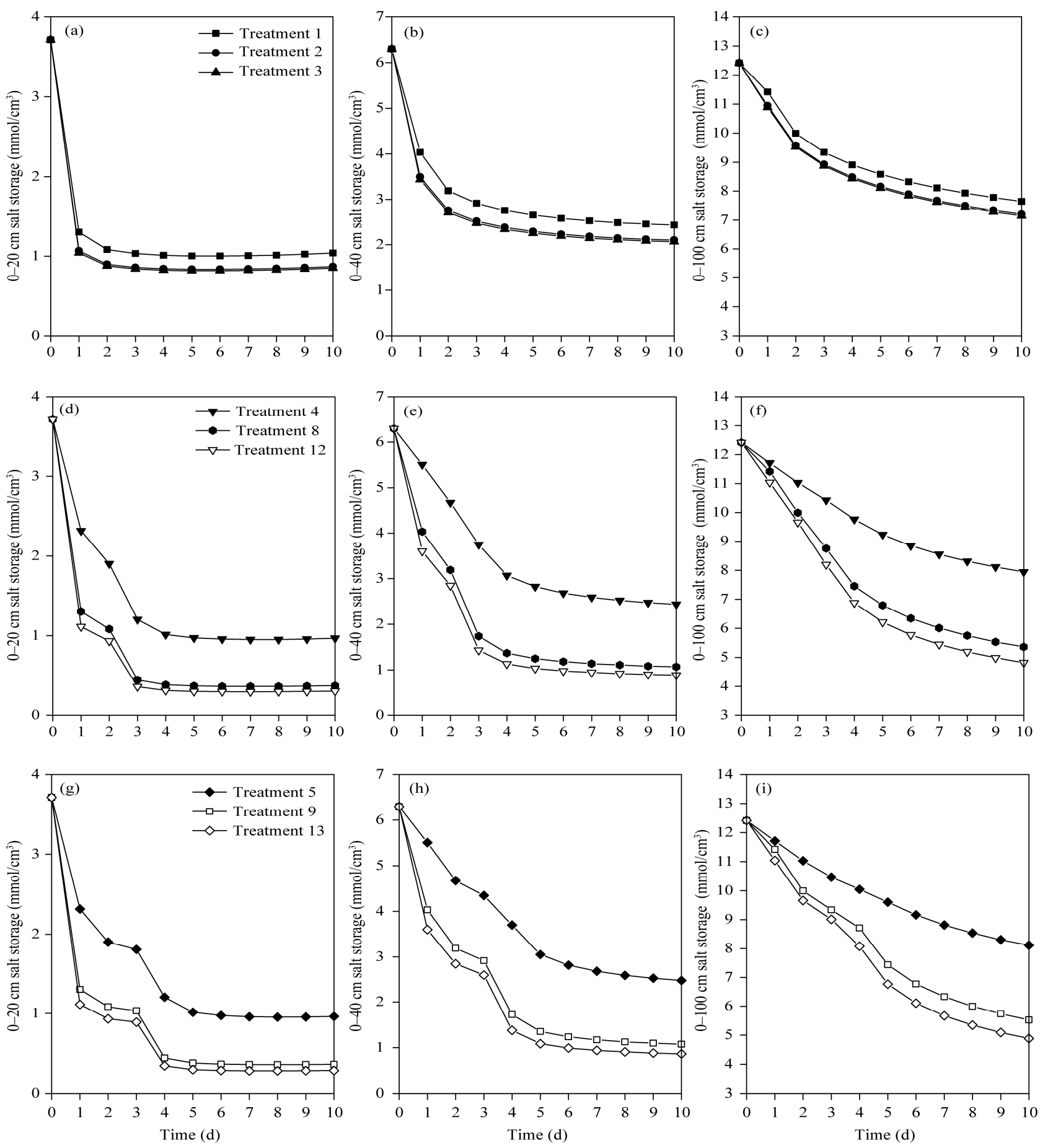

Fig. 5 Effect of irrigation amount on soil salt storage

is shown in Fig. 6. From the figure, we can see that the soil water storage increased and then decreased after irrigation. As the irrigation frequency increased, the number of soil water storage peaks continued to be equal to the number of instances of irrigation, but the peak margins decreased. Furthermore, the difference between the peak margins was more evident when the irrigation amount was small. Take the first soil water storage peak as an example. When the irrigation amount was $10 \mathrm{~cm}$, the soil water storage at 0-20, $0-40$, and $0-100 \mathrm{~cm}$ were less in treatment 4 than in treatment 1 by $4.72 \%, 5.58 \%$, and $8.83 \%$, respectively. 
However, when the irrigation amount was $20 \mathrm{~cm}$, the differences in the peak margins due to the increased irrigation frequency exhibited a considerable decline. Moreover, intermittent infiltration reduced the rate of soil water storage decline over time. For example, while the irrigation amount was $20 \mathrm{~cm}$ and the irrigation frequency was one, two, or three times, the water storage in the soil at $0-100 \mathrm{~cm}$ for each frequency of $0-10 \mathrm{~d}$ after irrigation had the following values: 28.44 $-43.00,30.65-42.99,33.77-40.77 \mathrm{~cm}$. For intermittent infiltration, Figs. 6d-f and Figs. $6 \mathrm{~g}-\mathrm{i}$ illustrate how the soil water storage changed over time when the irrigation amount was $20 \mathrm{~cm}$ and the irrigation intervals were $1 \mathrm{~d}$ and $2 \mathrm{~d}$. These figures demonstrate that as the irrigation intervals increased from $1 \mathrm{~d}$ to 2 d, water storage in soil of $0-20 \mathrm{~cm}$ in treatment 9 increased by $3.65 \%$ compared with the treatment 8 . Additionally, treatment 11 increased the soil water storage by $8.78 \%$ compared to the value after treatment 10 . Meanwhile, the water storage in the soil at $0-40$ and 0-100 $\mathrm{cm}$ increased slightly, which indicates that when the same irrigation amount and frequency are used, increasing the irrigation interval can help to increase the water storage capacity of thin soil (0-20 $\mathrm{cm})$.

As Figs. $7 \mathrm{a}-\mathrm{c}$ demonstrate, there is a clear relationship between soil water storage and time, as observed with an irrigation amount of $10 \mathrm{~cm}$ and a frequency of one, two, or three times. This finding demonstrates that soil salt storage was much less in treatment 1 than in treatment 4 and treatment 6 . Therefore, when the irrigation amount was small $(10 \mathrm{~cm})$, intermittent irrigation had a reduced leaching effect on soil salt storage than irrigating once. For an irrigation amount of $20 \mathrm{~cm}$, the opposite was true: intermittent irrigation had an increased leaching effect on soil salt storage than irrigating once. Specifically, $5 \mathrm{~d}$ after irrigation, whether examining thin soil $(0-20,0-40$ $\mathrm{cm})$ or the whole soil profile $(0-100 \mathrm{~cm})$, the soil salt storage indicated that intermittent irrigation was superior in terms of salt leaching. Compared with treatment 2 and $10 \mathrm{~d}$ after irrigation, the salt storage values in soil at $0-100 \mathrm{~cm}$ for treatment 9 and treatment 11 were reduced by $23.3 \%$ and $12.5 \%$, respectively. This reduction occurred because, during the irrigation in- terval, the dehydration of the top layer of soil led to an increase in the infiltration speed at the beginning of the next infiltration. Under infiltration conditions, solute is primarily transferred with moisture. Thus the intermittent infiltration can efficiently enhance the solute leaching effect (Ahmadi et al., 2010).

However, as Figs. $7 \mathrm{~d}-\mathrm{i}$ show, the soil salt storage was higher with treatment 10 and treatment 11 than with treatment 8 or treatment 9 . Meanwhile, the soil salt storage was higher with treatment 9 and treatment 11 than with treatment 8 and treatment 10 . In other words, when the same irrigation amount was used, increasing the irrigation frequency did not alter the leaching effect exerted by irrigation on salinity in soil profiles. There are two possible reasons for this observation. On the one hand, the dehydration of the top layer of soil may have led to the increase in the infiltration speed at the beginning of the following infiltration. This effect may have led to the densification of the top soil layer, thus preventing moisture and solute infiltration (Reedy et al., 1996). On the other hand, with intermittent infiltration, the quick moisture infiltration consisted mostly of macropore flow. The faster the rate of flow was, the more difficult it was for the flow to mix with solute in the pores, which reduced the capacity for carrying solute in this part of the flow (Brusseau et al., 1997).

Furthermore, some studies maintained that a small quantity of high-frequency, intermittent infiltration promoted deep seepage (Behera and Panda, 2009). Others, however, have argued that the irrigation method only led to moisture entrapment on the top layer of soil $(0-40 \mathrm{~cm})$, therefore, only substantial, one-time irrigation has the potential for deep seepage (Mermoud et al., 2005). Consequently, a comprehensive analysis and evaluation of the solute leaching effects of various irrigation methods must be conducted to find the optimal irrigation approach.

\subsection{Evaluation and analysis of salt leaching and the optimal irrigation regime}

Studies have indicated that irrigation can leach soil salt effectively and control soil salt content of root layer to meet the salt tolerance of crop (Ramos et al., 2012; Saririchi et al., 2012). Different irrigation regimes have different salt leaching effect (Nachabe et 



Fig. 6 Effects of irrigation times and intervals on soil water storage

al., 1999). Flood irrigation, for example, can surely decrease soil salt content, but it also has adverse effect on the environment. For one thing, flood irrigation needs a huge amount of water; for another, excessive irrigation might lead to deep seepage and increases the salinization risk of the aquifer (Kanzari et al., 2012).
Our previous analyses have proved that the salt leaching effect of intermittent irrigation is superior to that of irrigating once under the same irrigation amount. However, excessive irrigation frequencies might lead to insufficient mix of water and soil solute and reduce the capacity for carrying solute. Therefore, we should 



Fig. 7 Effect of irrigation times and intervals on soil salt storage

consider salt tolerance of crops, water saving irrigation and environmental conservation together when evaluating salt leaching and making irrigation regimes. The results of a regional survey of the Hetao Irrigation District conducted in July 2012 indicated that the main cash crops (sunflower and corn) could grow normally when the soil salt content was less than $0.3 \%$ $\left(0.1 \mathrm{mmol} / \mathrm{cm}^{3} \mathrm{NaCl}\right)$. Thus, we regard $0.3 \%$ soil salt content as the threshold for soil desalination and defined a function to evaluate the salt leaching effect as follows:

$$
y=a_{3} x_{3}-a_{1} x_{1}-a_{2} x_{2} .
$$

Here, $x_{1}, x_{2}, x_{3}$ are the soil salt storage at 0-20, 0-40, $0-100 \mathrm{~cm}$, respectively; $\alpha_{1}, \alpha_{2}, \alpha_{3}$ are weighting fac- 
tors corresponding to $x_{1}, x_{2}, x_{3}$; and we defined $a_{1}=0.5$, $a_{2}=0.3, a_{3}=0.2$ for this study. The higher the value of $\mathrm{y}$, the better the leaching effect.

To maximize the quality of the evaluation, we chose desalination depth $\left(\mathrm{H}_{\mathrm{ds}}\right)$, the maximum soil salt concentration $\left(\mathrm{C}_{\max }\right)$ and leaching effect function (y) as evaluation factors (Figs. 8 and 9). We defined the optimal irrigation regimes as those meeting the conditions of Eq. 13.

$$
\left\{\begin{array}{l}
H_{d s}>60 \mathrm{~cm}, \\
C_{\max }<0.1 \mathrm{mmol} / \mathrm{cm}^{3} \\
y>0.5
\end{array}\right.
$$



Fig. 8 Desalination depth and maximum salt concentration of each treatment

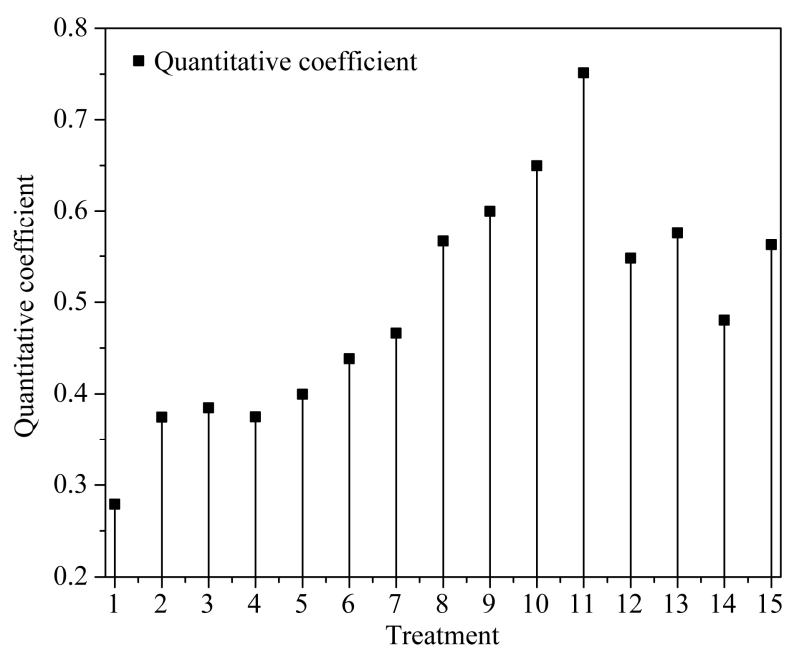

Fig. 9 The quantitative coefficient of salt leaching

The desalination depth, maximum salt concentration and quantitative coefficient of salt leaching are shown in Figs. 8 and 9. From Fig. 8, we could found the desalination depth increased with the increase of irrigation amount. More exactly, when the irrigation amount increased from 10 to $30 \mathrm{~cm}$, the desalination depth could increase by $354.54 \%$ (treatment 14 and treatment 6). Furthermore, the desalination depth decreased with the irrigation times when irrigation amounts were 10 and $20 \mathrm{~cm}$, respectively. However, when irrigation amount was $30 \mathrm{~cm}$, the contrary result was obtained. This might be because the content of the total dissolved solid of irrigation water was $0.2 \mathrm{~g} / \mathrm{L}$ and affected the salt redistribution significantly in higher irrigation amount $(30 \mathrm{~cm})$. Moreover, the change of maximum soil salt concentration was in accordance with the desalination depth. Figure 9 indicated that treatments with $20 \mathrm{~cm}$ irrigation amount had a higher quantitative coefficient of salt leaching than treatments with 10 and $30 \mathrm{~cm}$ irrigation amounts. What's more, the quantitative coefficients of treatments $8,9,10,11,12,13$, and 15 were all larger than 0.5 .

In addition, the above analysis $(3.1,3.2)$ indicated that excessive irrigation amount and irrigation frequencies could not promote soil salt leaching; thus, we do not recommend using an irrigation amount of 30 $\mathrm{cm}$ or high irrigation frequencies. By combining Figs. 8 and 9 with Eq. 13, we conclude that treatment 8 (20 $\mathrm{cm}, 2$ times, 1-d interval) is the optimal irrigation regime.

However, there are many other factors, such as irrigation water quality, climate condition, water table depth, crop types, and economic cost of irrigation, which affect irrigation regimes. Our study just analyzed reasonable irrigation regimes by field experiments and HYDRUS-1D simulation from the aspect of salt leaching. Further studies should combine agriculture development with environmental protection to make irrigation regimes for salinization areas.

\section{Conclusions}

With regard to soil salt leaching, effective use of different irrigation regimes requires knowledge of many coupled physical-chemical processes affecting soil conditions. The HYDRUS-1D model helps to generate 
this knowledge. In this study, we compared the simulation results of water and salt dynamics after irrigation with the observed values in the Hetao Irrigation District and found the simulation to be accurate. This result indicated that HYDRUS-1D is a useful tool for analysing agricultural water management in this region.

To better understand the effect of irrigation regimes on salt leaching and to find the optimal irrigation regime, we modelled 15 different irrigation scenarios with HYDRUS-1D. The results showed that irrigation amount did not have a significant effect on soil water storage but that increasing the irrigation amount could accelerate salt leaching. However, when the irrigation amount was larger than $20 \mathrm{~cm}$, the acceleration was not obvious. Compared with irrigating once, intermittent irrigation had a better effect on increasing soil water storage and salt leaching, but excessive irrigation frequencies and intervals did not improve salt leaching.

In addition, we defined the quantitative coefficient of salt leaching and desalination depth and established the evaluation conditions for salt leaching. By comparing each scenario, we found that the following irrigation regime might significantly increase salt leaching in the plough layer and decrease the risk of deep seepage and groundwater contamination: an irrigation amount of $20 \mathrm{~cm}$, two instances of irrigation and a $1 \mathrm{~d}$ interval. These findings were only based on HYDRUS-1D simulation, and further field experiments should be performed to verify and analyse the results.

\section{Acknowledgements}

This work was supported by the National "Twelfth Five-Year" Plan for Science \& Technology Support Program (2011BAD25B07), the State Natural Science Fund (51279142) and the Fundamental Research Fund for the Central Universities of the Ministry of Science and Technology, China. (2012206020206).

\section{References}

Ahmadi S H, Andersen M N, Plauborg F, et al. 2010. Effects of irrigation strategies and soils on field grown potatoes: yield and water productivity. Agricultural Water Management, 97: 1923-1930.
Behera S K, Panda R K. 2009. Effect of fertilization and irrigation schedule on water and fertilizer solute transport for wheat crop in a sub-humid sub-tropical region. Agriculture, Ecosystems \& Environment, 130: 141-155.

Brusseau M L, Hu Q, Srivastava R. 1997. Using flow interruption to identify factors causing non ideal contaminant transport. Journal of Contaminant Hydrology, 24: 205-219.

Crevoisier D, Popova Z, Mailhol J C, et al. 2008. Assessment and simulation of water and nitrogen transfer under furrow irrigation. Agricultural Water Management, 95: 354-366.

Dabach S, Lazarovitch N, Simunek J, et al. 2013. Numerical investigation of irrigation scheduling based on soil water status. Irrigation Science, 31: 27-36.

Feng Z Z, Wang X K, Feng Z W, et al. 2003. Influence of autumn irrigation on soil salt leaching of different farmlands in Hetao Irrigation District of Inner Mongolia. Rural Eco-envrionment, 19: 31-34.

Gerke H H, Genuchtenv M T. 1993. A dual-porosity model for simulating the preferential movement of water and solutes in structured porous media. Water Resources Research, 29: 305-320.

Ghassemi F, Jakeman A J, Nik H A. 1995. Salinization of Land and Water Resources. Human Gauses, Extent, Management and Case Studies. Sydney: New South Wales Press.

Kanzari S, Hachicha M, Bouhlila R, et al. 2012. Characterization and modeling of water movement and salts transfer in a semi-arid region of Tunisia (Bou Hajla, Kairouan)-salinization risk of soils and aquifers. Computers and Electronics in Agriculture, 86: 34-42.

Meng C H, Yang J Z. 2002. Experimental research on the radical selection of autumn irrigation norm in Hetao Irrigation District, China. Rural Water Research Hydropower, 5: 23-25.

Mermoud A, Tamini T D, Yacouba H. 2005. Impacts of different irrigation schedules on the water balance components of an onion crop in a semi-arid zone. Agricultural Water Management, 77: 282-295.

Nachabe M H, Ahuja L R, Butters G. 1999. Bromide transport under sprinkler and flood irrigation for no-till soil condition. Journal of Hydrology, 214: 8-17.

Neumann L E, Šimůnek J, Cook F J. 2011. Implementation of quadratic upstream interpolation schemes for solute transport into HYDRUS-1D. Environmental Modelling \& Software, 26: 1298-1308.

Ramos T B, Šimůnek J, Gonçalves M C, et al. 2011. Field evaluation of a multicomponent solute transport model in soils irrigated with saline waters. Journal of Hydrology, 407: 129-144.

Ramos T B, Castanheira N L, Goncalves M C, et al. 2012. Effect of combined use of brackish water and nitrogen fertilizer on biomass and sugar yield of sweet sorghum. Pedosphere, 22: 785-794.

Reedy O C, Jardine P M, Wilson G V. 1996. Quantifying the diffusive 
mass transfer of nonreactive solutes in columns of fractured saprolite using flow interruption. Soil Science Society of America Journal, 60: 1376-1384.

Sankaran S, Sonkamble S, Krishnakumar K, et al. 2012. Integrated approach for demarcating subsurface pollution and saline water intrusion zones in SIPCOT area: a case study from Cuddalore in Southern India. Environmental Monitoring and Assessment, 184: 5121-5138.

Saririchi T, Azad R R, Arabian D, et al. 2012. On the optimization of sphalerite bioleaching; the inspection of intermittent irrigation, type of agglomeration, feed formulation and their interactions on the bioleaching of low-grade zinc sulfide ores. Chemical Engineering Journal, 187: 217-221.

Schaap M G, Leij F J, van Genuchten M T. 2001. ROSETTA: a computer program for estimating soil hydraulic parameters with hierarchical pedotransfer functions. Journal of Hydrology, 251:
$163-176$

Simunek J, Jarvis N J, van Genuchten M T, et al. 2003. Review and comparison of models for describing non-equilibrium and preferential flow and transport in the vadose zone. Journal of Hydrology, 272: 14-35.

Skaggs T H, van Genuchten M T, Shouse P J, et al. 2006. Macroscopic approaches to root water uptake as a function of water and salinity stress. Agricultural Water Management, 86: 140-149.

Tafteh A, Sepaskhah A R. 2012. Application of HYDRUS-1D model for simulating water and nitrate leaching from continuous and alternate furrow irrigated rapeseed and maize fields. Agricultural Water Management, 113: 19-29.

Van Schilfgaarde J. 1994. Iirrigation-a blessing or a curse. Agricultural Water Management, 25: 203-219.

Yu L Y, Lu Y Y, An S B. 2010. Research progress of bicarbonate and carbonate determination. Westleather, 32: 48-52. 